\title{
Design and Realization of Virtual Training System for New Type Howitzer
}

\author{
Pin Duan \\ Wuhan Military Representative Office \\ General Armament Department of PLA \\ Wuhan, China \\ dpindpindpin@163.com
}

Qi Guo

Wuhan Military Representative Office

General Armament Department of PLA

Wuhan, China

gqguoqi1978@163.com

\author{
Yong Jin \\ Wuhan Military Representative Office \\ General Armament Department of PLA \\ Wuhan, China \\ jzy5168@yahoo.com.cn
}

\author{
Lei Pang \\ Wuhan Military Representative Office \\ General Armament Department of PLA \\ Wuhan, China \\ nicholas530@163.com
}

\begin{abstract}
Virtual training system is important to improve the force operational capability. Due to urgent training needs for new type howitzer, the virtual training system was established based on analysis of a variety of training methods. From the system characteristic, the function modules were designed. Methods were specially expounded in realizing the ballistic function expression and setting up the troubles database. The process is shown to transform the trajectory coordinate system into the earth coordinate system. Meanwhile, it is suggested that troubleshooting training should be included into equipment training system. The system realizes the functions, such as threedimensional modeling, force generation, trajectory computation, troubles database establishment, evaluation, operation plan's preparation and so on. The system is good at training effect through military trial.
\end{abstract}

Keywords-Ballistic function; Howitzer; Troubleshooting; Virtual training

\section{INTRODUCTION}

The howitzer is new equipment, which needs lot of training as soon as possible to forming the battle effectiveness because of its powerful functions and complex structures. There are four ways to adopted, real equipment training, simulation training, pure virtual training [1] and virtual training. Real equipment training completely fits the facticity, the reliability, and the characteristic of equipment, but it's expensive, insecure and especially attrite to equipment; Through software, simulation training establishes communication between certain hardware configuration, such as lever, dashboard, seat and so on, in this way at a lower cost, but less commonly-used; Pure virtual training is poor at fitting real equipment and lack of the immersion sense, because trainees need to control the virtual models by the mouse and keyboard on computer platform; The last way is virtual training, where trainees operate the virtual models by interactive devices (data glove, helmet, location tracking, etc.), it's true, safe, inexpensive and commonly-used, wherefore this system is designed and realized in this way.

\section{PlAN AND PRINCIPLE}

Design and realization is a complex process for new type howitzer training system, and it is impossible to cover everything. This system mainly study on driving, shooting and troubleshooting of single howitzer. Design complies with the following principles $[2,3]$.

Object: training system is designed for single howitzer operations, which the joint operations aren't considered. Face on driver, shooting operator and maintenance personnel to establish user interface and training environment.

Authenticity: Visual experiences of virtual in-vehicle devices directly contact with the operator should comply with actual weapon systems; furthermore, three dimensional terrain and ballistic trajectory, enemy target and malfunction should be as real as possible.

Openness: The system with familiar interface allows third part development. The system function make up of currency modules combining with specialness modules which be designed only for specific howitzer.

Interoperability: the subsystems should adopt a unified structural framework, the expression method and the interface specification to ensure that the system would be organic coupling.

\section{FUNCTION AND FLOW}

The system's function consist of teaching demonstration, devices calibration, individual subject training, integrated training, evaluation and third part development [4, 5]. Fig. 1 illuminates the system's function and the flow of shooting training. 


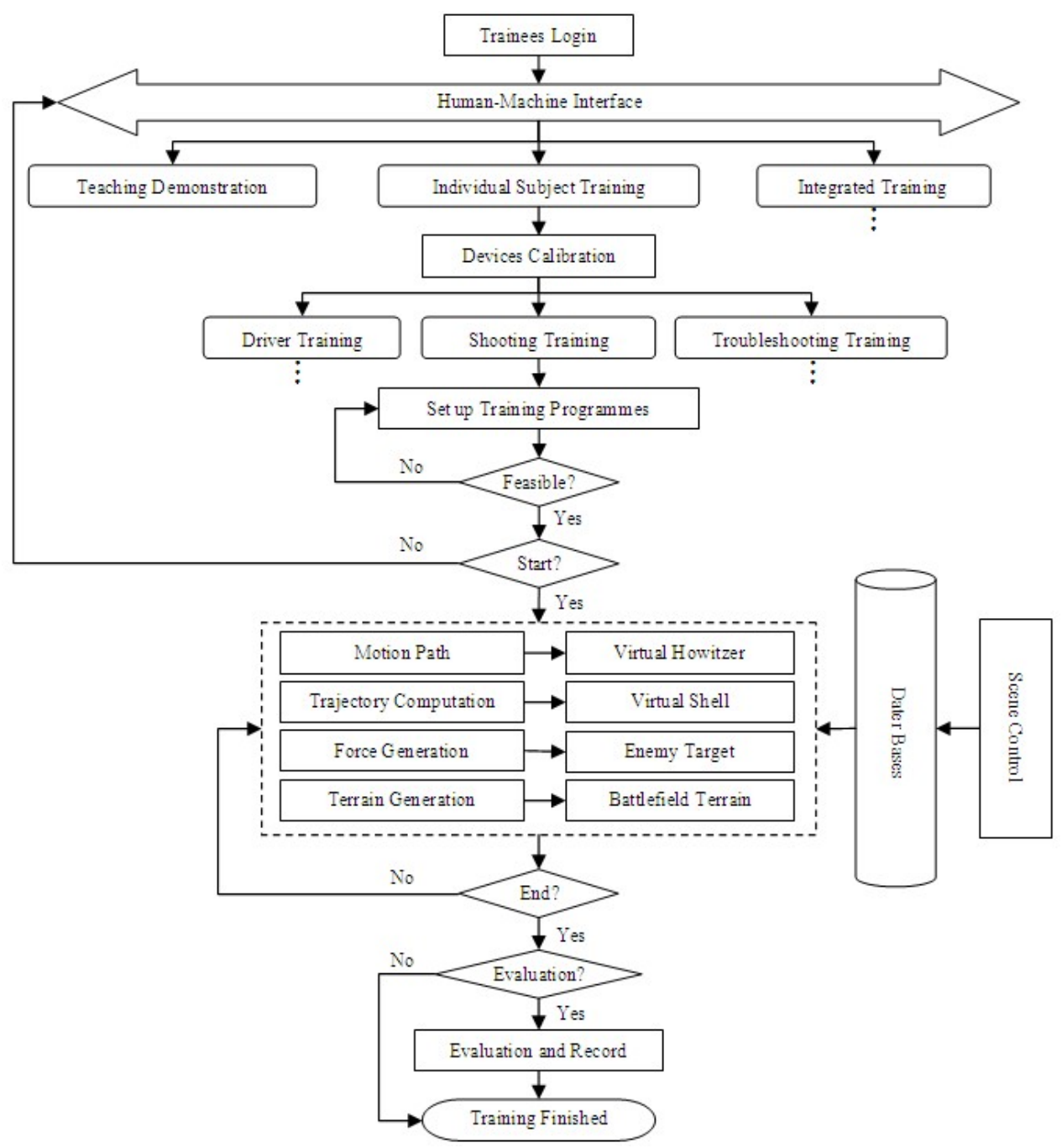

Figure 1. System's functions and shooting training flow

Teaching demonstration demonstrates structure, functions and working principle, operational processes and job functions of weapon system and sub-systems by virtual model [6].

Devices calibration is preparatory work before training, including location tracking device calibration, data glove gesture recognition and correction [7].

Individual subject training takes jobs training for driver, shooting operator and maintenance personnel, including driver training, shooting training and troubleshooting training.

Integrated training takes flow for trainees to operate as real equipment training based on combat plans.

Evaluation gives grades of Individual subject training and integrated training.

\section{CRUX POINTS}

\section{A. Ballistic Function Expression}

In order to truly reflect the shooting process, it is necessary for function expression to show the shell flying in virtual battlefield environment, and which function takes basis for computer to control and display the shell. In case of acceleration due to gravity is constant, the vacuum trajectory equation of mass's center without Earth's curvature and rotation is (1) [8].

$$
\left\{\begin{array}{l}
\frac{d v}{d t}=\mathrm{a}-\mathrm{g} \sin \theta \\
\frac{d \theta}{d t}=-\mathrm{g} \cos \theta / v \\
\frac{d x}{d t}=v \cos \theta \\
\frac{d y}{d t}=v \sin \theta
\end{array} .\right.
$$

Where a is constant as the thrust acceleration, $v$ as the shell speed, $g$ as the acceleration due to gravity constant, $\theta$ as the included angle of the shell flight direction and the horizontal plane, $t$ as time, $x$ as the horizontal distance of the 
shell from the muzzle, and $y$ as the vertical distance of the shell from the muzzle.

In case of a equals 0 , namely the shell in the non-thrust force situation, equation (1) shows the common shell trajectory.
The system takes common shell trajectory as example to establish ballistic models.

So, the explicit function equation [8] with $x$ as independent variable is shown in (2).

$$
\left\{\begin{array}{l}
t-t_{A}=\left(x-x_{A}\right) /\left(v_{A} \cos \theta_{A}\right) \\
y-y_{A}=\left(x-x_{A}\right) \operatorname{tg} \theta_{A}-\mathrm{g}\left(x-x_{A}\right)^{2} /\left(2 v_{A}^{2} \cos ^{2} \theta_{A}\right) \\
\operatorname{tg} \theta=\operatorname{tg} \theta_{A}-\mathrm{g}\left(x-x_{A}\right) /\left(v_{A}^{2} \cos ^{2} \theta_{A}\right) \\
v=v_{A} \cos \theta_{A} \sqrt{1+\operatorname{tg}^{2} \theta}=\sqrt{v_{A}^{2}-2 \operatorname{gtg} \theta_{A}\left(x-x_{A}\right)+\mathrm{g}^{2}\left(x-x_{A}\right)^{2} /\left(v_{A} \cos \theta_{A}\right)^{2}}
\end{array} .\right.
$$

Where A is the fiducial mark of the muzzle. However, equation (3) is useful only for establishing system ballistic.

$$
y-y_{A}=\left(x-x_{A}\right) \operatorname{tg} \theta_{A}-\mathrm{g}\left(x-x_{A}\right)^{2} /\left(2 v_{A}^{2} \cos ^{2} \theta_{A}\right) .
$$

In order to simplify operations, suppose $x_{A}$ and $y_{A}$ all equal 0 . Then, equation (3) is converted to (4)

$$
y=x \operatorname{tg} \theta_{A}-\mathrm{g} x^{2} /\left(2 v_{A}^{2} \cos ^{2} \theta_{A}\right) .
$$

For a unified interface in this system, it is necessary to transform the trajectory coordinate system into the earth coordinate system. Suppose the angle between zero line and $\mathrm{X}$ axis of earth coordinate system is $\beta$, and the shooting angle is $\gamma$ which is negative in left of zero line opposite positive in right, so, the angle between direction of shooting and $\mathrm{X}$ axis is (5).

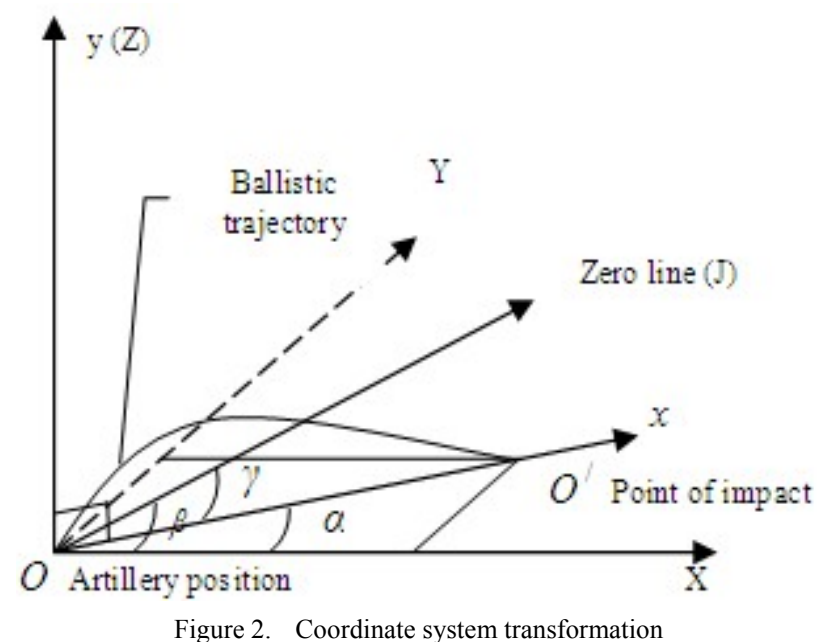

Figure 2. Coordinate system transformation

$$
\alpha=\beta-\gamma
$$

Fig. 2 demonstrates (6) and (7).

$$
x=\sqrt{X^{2}+Y^{2}} .
$$

$$
Y=X \operatorname{tg} \alpha
$$

Then

$$
x=X / \cos \alpha .
$$

Equation (8) into (4),

$$
y=X\left(2 v_{A}^{2} \sin \theta_{A} \cos \theta_{A} \cos \alpha-\mathrm{g} X\right) /\left(2 v_{A}^{2} \cos ^{2} \theta_{A} \cos ^{2} \alpha\right) .
$$

Where $y \geq 0$, the range of $X$ is $(0$, $\left.2 v_{A}^{2} \sin \theta_{A} \cos \theta_{A} \cos \alpha / \mathrm{g}\right)$.

Take (5) into Equations (7) and (9), and replace $y$ with $Z$ for understanding.

Equation (10) is the shell function about geodetic coordinates $(X, Y, Z)$.

Based on the last equations, it's easy to draw the range and the ballistic curve of shells with different charge as long as get necessary initial conditions, and to display in virtual battlefield environments through computers. Of course, times are necessary for system to simulation the flying shell, which are demonstrated in (11). 


$$
\begin{gathered}
\left\{\begin{array}{l}
Z=X\left(2 v_{A}^{2} \sin \theta_{A} \cos \theta_{A} \cos (\beta-\gamma)-\mathrm{g} X\right) /\left(2 v_{A}^{2} \cos ^{2} \theta_{A} \cos ^{2}(\beta-\gamma)\right) \\
Y=X \operatorname{tg}(\beta-\gamma)
\end{array} .\right. \\
T=x /\left(v_{A} \cos \theta_{A}\right)=\left(\operatorname{tg} \theta_{A} / \mathrm{g}\right) /\left(v_{A} \cos \theta_{A}\right)=\sin \theta_{A} /\left(\mathrm{g} v_{A} \cos ^{2} \theta_{A}\right) .
\end{gathered}
$$

\section{B. Fault Databases Generation}

Effective realization of fault simulation and troubleshooting is an important aspect of equipment training system, as well as difficulties of simulation. Previous training systems are focused on operations, while ignoring the fault maintenance. In fact, gunners can even remove some simple troubles by themselves without specialized repair agencies. Therefore troubleshooting training should be included in the equipment training system.

Fault databases [3] establishment is difficult for troubleshooting of virtual training system, which includes expert solutions and animated simulations for troubles. Based on equipment maintenance manuals and Feedback information from users, fault databases are finished including of Artillery types, parts names and No., fault codes, fault phenomenon, animated descriptions and solutions, as shown in Table I.

According to fault codes from databases, virtual system shows the fault phenomenon in the maintaining process, such as breech block not in place and button malfunction. Trainees go to do other tasks after to solve the fault based on its phenomenon. In this way, trainees can be improved the ability to react and the capacity of dealing with sudden faults.

TABLE I.

\begin{tabular}{|c|c|c|c|c|c|}
\hline $\begin{array}{l}\text { Artillery } \\
\text { Type }\end{array}$ & $\begin{array}{c}\text { Parts Name and } \\
\text { No. }\end{array}$ & $\begin{array}{l}\text { Fault } \\
\text { Code }\end{array}$ & Fault Phenomenon & $\begin{array}{c}\text { Animated } \\
\text { Description }\end{array}$ & Solution \\
\hline \multirow{7}{*}{$\begin{array}{l}\text { New type } \\
\text { howitzer }\end{array}$} & \multirow{4}{*}{$\begin{array}{l}\text { Counter recoil } \\
\text { mechanism } 01\end{array}$} & 001 & $\begin{array}{l}\text { The bolt of oil filler hole leaks } \\
\text { fluid in the recoil brake lever. }\end{array}$ & 01001.avi & $\begin{array}{l}\text { 1. Make sure the bolt of oil filler hole has been tightened; } \\
\text { 2. If sealing ring damaged, replace. }\end{array}$ \\
\hline & & 002 & $\begin{array}{l}\text { The bolt of oil drain hole leaks } \\
\text { fluid in the recoil brake lever. }\end{array}$ & 01002.avi & $\begin{array}{l}\text { 1. Make sure the bolt of oil drain hole has been tightened; } \\
\text { 2. If sealing ring damaged, replace. }\end{array}$ \\
\hline & & 003 & $\begin{array}{l}\text { The recuperator charge valve } \\
\text { leaks fluid and air. }\end{array}$ & 01003.avi & $\begin{array}{l}\text { 1. Confirm the charge valve has been tightened; } \\
\text { 2. Confirm sealing ring is OK; } \\
\text { 3. Replace the charge valve. }\end{array}$ \\
\hline & & 004 & Counter-recoil too much. & 01004.avi & $\begin{array}{l}\text { 1. Check the recoil fluid volume; } \\
\text { 2. Adjust air pressure of recuperator. }\end{array}$ \\
\hline & \multirow{3}{*}{$\begin{array}{c}\text { Fire fighting and } \\
\text { explosion } \\
\text { suppression } \\
\text { devices } 02\end{array}$} & 001 & The power light is out of work. & 02001.avi & $\begin{array}{l}\text { 1. Check all power switches; } \\
\text { 2. Check circuit. }\end{array}$ \\
\hline & & 002 & Trouble lamp is on. & 02002.avi & $\begin{array}{l}\text { Immediately turn off and check the cause of the } \\
\text { malfunction. }\end{array}$ \\
\hline & & 003 & $\begin{array}{l}\text { When turn on switch, a few lights } \\
\text { are out of work at all times. }\end{array}$ & 02003.avi & $\begin{array}{l}\text { 1. Make sure bulbs to be OK; } \\
\text { 2. Check circuit. }\end{array}$ \\
\hline
\end{tabular}

FAULT DATABASE

\section{CONCLUSIONS}

With the continuous upgrading of high technology weapons, there are more and more training systems with their advantages and disadvantages. This paper focuses on the ballistic function of the virtual system and transforms the trajectory coordinate system into the earth coordinate system. The paper suggests that troubleshooting training should be included into equipment training system to improve the comprehensive qualities for operators and maintain personals. Users believe the system meets the application requirements.

\section{REFERENCES}

[1] D. D. Ding, F. M. Zeng, J. M. Wu and G. F. Yu, "Research on purevirtual marine power pant simulation system," Computer Simulation, Vol. 24, No.2, pp.273-276, 2007. (In Chinese)

[2] H. M. Guo, M. Yang, L. Li, M. Xiang, M. Q. Li and J. Y. Wang, "Design and implementation of the training simulator for the surface-to- air missile," Journal of System Simulation, Vol. 15, No.1, pp.69-71, 2003. (In Chinese)

[3] Y. K. Sun and Z. Y. Xiong, "Simulation design and realization for new type destroyer and frigate's operational system," Journal of System Simulation, Vol. 24, No.4, pp.902-906, 2012. (In Chinese)

[4] Z. Y. Chen, W. Wang, S. R. Tan and M. J. Zhang, "Design and implementation of training simulation system for surface-to-air missile," Computer Simulation, Vol. 26, No.6, pp.88-91, 2009. (In Chinese)

[5] L. Guan, Y. W. Shao, C. Y. Hao, Y. Wang, L. Zhang and X. P. Li, "The research of virtual war training system based on Direct3D," Journal of Projectiles Rockets Missiles and Guidance, Vol. 26, No.2, pp.107-109, 2006. (In Chinese)

[6] B. Tan, S. B. Guo and B. Fu, "Design of equipment operation training simulation system based on HLA," Journal of System Simulation, Vol. 23, No.1, pp.177-179, 2011. (In Chinese)

[7] MultiGen-Paradigm, Inc., Vega Prime Programmer's Guide, US: MultiGen-Paradigm, Inc., 2007.

[8] Z. Y. Yang, "An exact explicit solution of the vacuum exterior ballistics of the thrusted projectiles," Acta Armamentarii, Vol. 3, No.3, pp.23-30, 1982. (In Chinese) 